\title{
Criticality in Bulk Metallic Glass Constituent Elements
}

\author{
RODRIGO MIGUEL OJEDA MOTA, ${ }^{1}$ T.E. GRAEDEL,${ }^{2}$ EVGENIA \\ PEKARSKAYA, ${ }^{3}$ and JAN SCHROERS ${ }^{1,4}$ \\ 1.-Department of Mechanical Engineering, Yale University, New Haven, CT 06510, USA \\ 2.-School of Forestry and Environmental Studies, Yale University, New Haven, CT, USA \\ 3.—Supercool Metals, New Haven, CT 06511, USA. 4.—e-mail: jan.schroers@yale.edu
}

Bulk metallic glasses (BMGs), which readily form amorphous phases during solidification, are increasingly being used in first applications of watch components, electronic casings, and sporting goods. The compositions of BMGs typically include four to six elements. Various political and geological factors have recently led to supply disruptions for several metals, including some present in BMG compositions. In this work, we assess the "criticality" of 22 technologically interesting BMG compositions, compare the results with those for three common engineering alloy groups, and derive recommendations for BMG composition choices from a criticality perspective. The criticality of BMGs is found to be generally much higher compared with those for the established engineering alloys. Therefore, criticality concerns should also be considered in the choice between existing and developing novel BMGs.

\section{INTRODUCTION}

Bulk metallic glasses (BMGs) are alloys that readily form an amorphous phase during solidification. ${ }^{1,2}$ The adjective "readily" indicates solidification of an alloy in amorphous form with at least $1 \mathrm{~mm}$ thickness, which approximately corresponds to cooling rates for vitrification below $1000 \mathrm{~K} / \mathrm{s}^{2}$ BMGs comprise transition metals that are often combined with metalloids, which are then combined in a multicomponent alloy., ${ }^{3,4}$ The amorphous structure results in very high strength and elasticity, properties that are often paired with toughness, ${ }^{5}$ flaw tolerance ${ }^{6}$ high corrosion resistance, ${ }^{7-10}$ biocompatibility, ${ }^{11-13}$ and favorable electrochemical behavior. ${ }^{14}$ These properties have triggered wide commercial exploration of BMGs. ${ }^{15-17}$ One of the most unusual and useful attributes of BMGs are that they escape the typical materials trade-off of processibility versus properties. ${ }^{18}$ The high stability against crystallization results in a supercooled liquid region that enables thermoplastic forming (TPF) similar to the processing of thermoplastics. ${ }^{18}$ Thus, BMGs can be considered high-strength metals that can be processed like plastics. ${ }^{18,19}$ TPF-based processes for BMGs like blow-molding, ${ }^{18}$ extrusion, ${ }^{20,21}$ compression molding, ${ }^{22,23}$ micro- and nano-molding, ${ }^{1724}$ and hot-rolling ${ }^{25}$ permit BMGs to be formed into many complex shapes on various length scales.
It has been estimated that more than 10 million alloys form BMGs. ${ }^{26}$ The selection criteria for BMGforming elements include their relative size, ${ }^{2,4,27,28}$ their thermodynamic attraction quantified in the pairwise heat of mixing, ${ }^{2,29,30}$ and the stability of the liquid compared with the crystal. ${ }^{31-33}$ The latter is quantified by the suppression of the liquidus temperature compared with the weighted rule of mixing of the melting temperature of the constituents. These complex selection rules for BMG constituents do not a priori identify or disqualify elements. Rather, their suitability is primarily determined by the interplay of the constituents rather than their inherent properties. ${ }^{4}$ Overall, more than 30 elements have been reported to be present in BMGs. ${ }^{26}$

\section{GROWTH OF BMG COMMERCIAL USAGE}

The combination of BMG properties with thermoplastic formability has led to rapidly growing commercial interest. Early adaptation includes the use of BMGs in sporting goods, watch components, and electronic casings. ${ }^{16,19,34,35}$ The focus of the early applications has been on the small scale, typically below $10 \mathrm{~cm}$. This length scale has its origin in limited supply chains, high materials costs for most advanced BMGs, and a limited processing infrastructure. ${ }^{15,36}$ In principle, considering BMG 
constituent selection criteria and the wide range of potential $\mathrm{BMGs}$, the $\mathrm{BMG}$ application range is limited in thickness but not in size. Current understanding suggests that it may be most promising to use BMGs in applications where at least one dimension is smaller than $\sim 1 \mathrm{~mm} .{ }^{37}$ In such dimensions, BMGs offer significant ductility in addition to the earlier discussed property advantages. ${ }^{37}$ Such geometries are typical in aerospace, automotive, and space applications, as well as in a wide range of casings.

To provide perspective on possible increasing metal demand for constitutive BMG elements, we address growth trends in current activities in the commercial and academic arena. As an example, we consider electronic casings for mobile phones, where because of current size limitations in fabricating BMGs, most near-term commercial activities have occurred. One could argue that BMGs could constitute some $20 \%$ of the mobile casing market based on current metal usage and the trend to higher performance materials. With the annual global sales of cell phones at $\sim 1.5$ billion, and $\sim 50$ g per phone for the casing fabrication, the material demand is of the order of 75,000 metric tons (75 Gg) of BMG constituents annually. Other electronic casings and larger size applications in aerospace and automotive sectors are less quantifiable and likely will not be widely employed within the next 3 years. When they are, however, these applications will consume dramatically larger quantities of materials than BMGs do at present. Because some BMG formulations contain elements with tiny annual productions (e.g., $\mathrm{Be}^{38}$ and $\mathrm{Er}^{39}$ ), it behooves materials scientists to be aware of the potential supply limitations of candidate BMG constituents.

\section{CRITICALITY}

One attribute of BMG-forming mixtures that has not heretofore been considered in assessing BMG commercial viability and suitability is elemental criticality. Criticality is defined as "essential to economic development but having limited supplies and being subject to supply-demand imbalances". ${ }^{40}$ Thus, in theory, an element may be ideal for glass formation or a BMGs' property or application, but if that application becomes robustly deployed, limitations may be imposed by factors such as geological availability or toxicological attributes that could constrain use in BMG applications.

Despite one's intuition that it should be straightforward to designate one element as critical and another as not, determining criticality turns out to be very challenging indeed. ${ }^{41}$ This is because criticality depends not only on geological abundance but also on a host of other factors such as the potential for substitution, the degree to which ore deposits are geopolitically concentrated, the state of mining technology, the amount of regulatory oversight, geopolitical initiatives, and degree of governmental instability. ${ }^{40}$ As various organizations (e.g., Refs. 41-43) have attempted to determine resource criticality in recent years, various metrics and methodological approaches have been chosen. The predictable result has been that criticality designations have differed widely. ${ }^{44}$

The criticality methodology that we employ in the present work $^{45}$ was designed to be applicable to users of different organizational types (e.g., corporations, national governments, and global-level analysts), and it is purposely flexible to allow user control over aspects of the methodology such as the relative weighting of variables. As with any evaluation employing an aggregation of indicators, the choice of those indicators is, in part, an exercise in judgment, ${ }^{46}$ but alternative choices have been evaluated over several years and we believe all of our final choices to be defendable in detail. The methodology locates individual metals in a three-dimensional "criticality space," the axes being supply risk, Environmental Implications, and Vulnerability to Supply Restriction (Fig. 1). Evaluations of each axis involve numerous criticality-related indicators, each measured on a $0-100$ scale and weighted equally. For the evaluation of the criticality of BMG constituents, we regard medium-term supply risk as the most important characteristic to be assessed. Its assessment involves three components and six indicators, as shown in Fig. 1. (Each of the indicators is discussed in detail in Ref. 45).

The methodology has been applied to 62 metals and metalloids (hereafter termed "elements" for simplicity of exposition)—essentially all elements except highly soluble alkalis and halogens, the noble gases, nature's "grand nutrients" (carbon, nitrogen, oxygen, phosphorus, sulfur), and radioactive elements such as radium and francium that are of little technological use. Detailed results for individual groups of elements have been published separately. ${ }^{4-53}$ In general, the elements with the highest crustal abundances (iron, aluminum, copper, etc.) are of little concern from a criticality perspective. Those that are rare, especially if they are only available as by-products of the major metals, rank higher in the criticality evaluation.

To apply the concept of criticality to BMGs, we identified 32 elements as potential constituents in BMG alloys. Figure 2 depicts their supply risk and their most significant supply range matrix.

\section{APPLICATION OF THE CRITICALITY CONCEPT TO BULK METALLIC GLASSES}

How can metal criticality information be useful in the selection of constituents for BMGs? We propose that a promising approach is to plot data from criticality assessments of metals against some suitable characteristic parameter for a BMG composition (or perhaps a BMG family). The concept is illustrated in Fig. 3. In general, one would like to choose a BMG composition with a 


\section{Components}

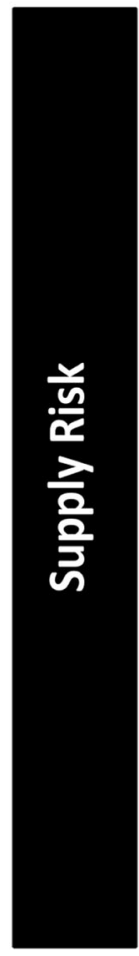

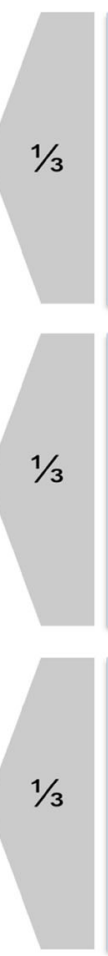

Weight

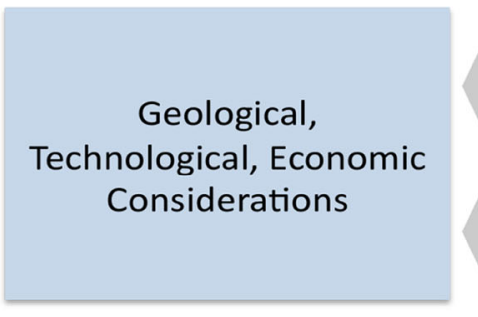

Social \& Regulatory

Considerations

Geopolitical

Considerations

\section{Factors}
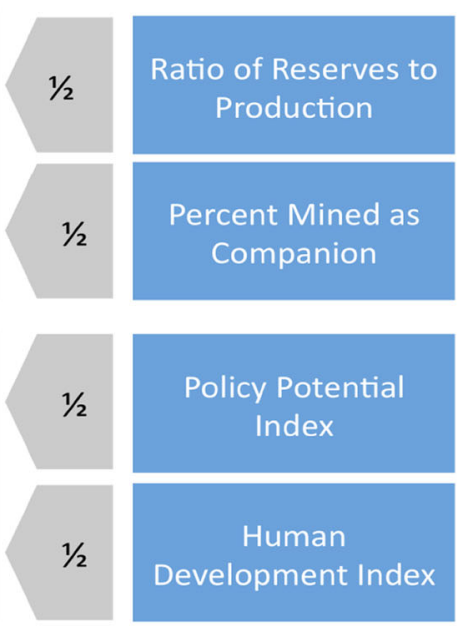

Worldwide

Governance Indicators:

Political Stability

Global Supply

Concentration

Fig. 1. Diagram of the supply risk axis of criticality, its components, and its constituent indicators, as used for a medium-term perspective.

\begin{tabular}{|c|c|c|c|c|c|c|c|c|c|c|c|c|c|c|c|c|c|}
\hline 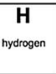 & 2 & & & \begin{tabular}{|c|} 
SR\# \\
Si
\end{tabular} & & & $\begin{array}{l}0 .-100, h \mathrm{hl} \\
\mathrm{HDI}=\mathrm{h}\end{array}$ & $\begin{array}{l}\text { er num } \\
\text { an dev }\end{array}$ & $\begin{array}{l}\text { rs are } \\
\text { pment }\end{array}$ & & & 13 & 14 & 15 & 16 & 17 & $\underset{\substack{\mathrm{He} \text { heium } \\
\text { nat }}}{\mathrm{He}}$ \\
\hline$\underset{\text { hrivem }}{\mathrm{Li}}$ & $\begin{array}{c}8 \\
\text { Beeplum } \\
\text { bsc } \\
\text { Gsc }\end{array}$ & & & $\begin{array}{l}\text { sillonn } \\
\text { SR motric }\end{array}$ & & & 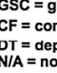 & 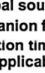 & $\begin{array}{l}\text { once } \\
\text { on }\end{array}$ & & & 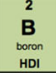 & $\underset{\text { catron }}{\mathbf{C}} \underset{\text { NA }}{\mathbf{C}}$ & $\underset{\text { ntrogon }}{\mathbf{N}}$ & $\underset{\text { oxpgen }}{O}$ & $\underset{\substack{\text { svouine } \\
F}}{F}$ & 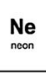 \\
\hline$\underset{\text { socoum }}{\mathrm{Na}}$ & 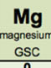 & 3 & 4 & 5 & 6 & 7 & 8 & 9 & 10 & 11 & 12 & $\begin{array}{c}\text { Aluminum } \\
\text { HDI } \\
\text { HDI }\end{array}$ & $\underset{\substack{\text { sicoon } \\
\text { NAA }}}{\mathbf{S i}}$ & 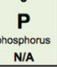 & $\underset{\text { suturer }}{\mathbf{S}}$ & $\underset{\text { chlorine }}{\mathbf{C I}}$ & $\underset{\text { argon }}{A r}$ \\
\hline $\mathbf{K}$ & $\begin{array}{c}\text { Calcum } \\
\text { calcum } \\
\text { N/A }\end{array}$ & $\begin{array}{l}\text { scandium } \\
\text { sc } \\
\text { CF }\end{array}$ & $\begin{array}{c}\text { tutium } \\
\text { tinium } \\
\text { HOI }\end{array}$ & $\underset{\text { vanadun }}{\mathbf{V}}$ & $\begin{array}{c}\text { Crror } \\
\text { Drum } \\
\text { DT }\end{array}$ & $\begin{array}{c}\text { Manangese } \\
\text { mate } \\
\text { DT }\end{array}$ & $\begin{array}{l}\mathrm{O} \\
\mathrm{Fe} \\
\text { ion } \\
\mathrm{GSC}\end{array}$ & $\begin{array}{c}\text { Co } \\
\text { cotal } \\
\text { CF }\end{array}$ & $\begin{array}{c}\text { Nit } \\
\text { nictol } \\
\text { HDI }\end{array}$ & $\begin{array}{c}\text { Cu } \\
\text { Copoer } \\
\text { DT }\end{array}$ & $\begin{array}{c}\mathbf{Z} \text { Zn } \\
\text { inco } \\
\text { DT }\end{array}$ & $\underset{\substack{\text { gallium } \\
\mathbf{G a}}}{ }$ & $\underset{C F}{G e}$ & $\underset{\text { Assomic }}{\text { As }}$ & $\underset{\text { selenium }}{\text { Se }}$ & $\underset{\text { bromine }}{\mathrm{Br}}$ & $\underset{\text { knpton }}{\mathrm{Kr}}$ \\
\hline$\underset{\text { nubicum }}{\mathbf{R b}}$ & $\underset{\text { strontium }}{\mathrm{Sr}}$ & 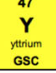 & $\begin{array}{c}\text { Ziror } \\
\text { zironin } \\
\text { CF }\end{array}$ & 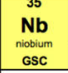 & 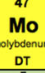 & Tc & Ru & $\mathbf{R h}$ & $\begin{array}{c}\text { Pold } \\
\text { Paldoum } \\
\text { CF }\end{array}$ & $\begin{array}{l}\mathbf{7 8} \\
\text { Agg } \\
\text { salor } \\
\text { DT }\end{array}$ & $\underset{\text { cddinm }}{\mathrm{Cd}}$ & $\begin{array}{l}\text { In } \\
\text { In } \\
\text { nitim } \\
C \text { CF }\end{array}$ & $\begin{array}{l}\text { Sn } \\
\text { Sn } \\
\text { th } \\
\text { DT }\end{array}$ & $\begin{array}{c}\text { Sb } \\
\text { anfinony } \\
\text { or }\end{array}$ & $\begin{array}{c}\text { Te } \\
\text { telurium } \\
\end{array}$ & $\underset{\text { iodine }}{1}$ & $\underset{\text { Xamen }}{\mathbf{X e}}$ \\
\hline$\underset{\text { cosium }}{\text { Cs }}$ & $\underset{\substack{\text { barium } \\
\mathrm{Ba}}}{ }$ & $\underset{\text { Iannanum }}{\mathrm{La}}$ & $\underset{\substack{\text { hetfium } \\
\text { CFF }}}{\mathrm{Hi}}$ & 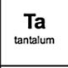 & $\begin{array}{c}\text { Wingston } \\
\text { Gsc } \\
\text { Gsc }\end{array}$ & $\underset{\text { menium }}{\mathbf{R e}}$ & Os & $\underset{\text { infoum }}{\text { Ir }}$ & $\begin{array}{l}\text { Patt } \\
\text { bataum } \\
\text { Gsc }\end{array}$ & $\begin{array}{l}\text { Au } \\
\text { gut } \\
\text { HDI }\end{array}$ & $\underset{\text { merasy }}{\mathrm{Hg}}$ & $\underset{\text { trallum }}{\mathrm{TI}}$ & $\underset{\substack{\log d \\
\mathbf{P b}}}{ }$ & $\underset{\text { Desmuth }}{\mathrm{Bi}}$ & poonim & $\underset{\text { astatio }}{\text { At }}$ & $\underset{r \text { rason }}{\mathrm{Rn}}$ \\
\hline $\mathrm{Fr}$ & $\mathbf{R a}$ & $\mathbf{A C}$ & $\mathrm{Rf}$ & Db & $\mathrm{Sg}$ & Bh & Hs & Mt & Ds & $\mathbf{R g}$ & Cn & Nh & FI & Mc & Lv & Ts & Og \\
\hline
\end{tabular}

\section{Score Scale}

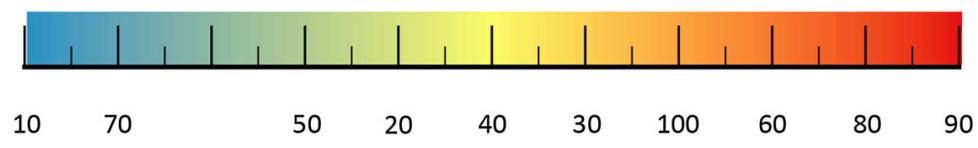

Fig. 2. Summary of the supply risk index of criticality and the corresponding matrix for the 32 practical constituents' elements in BMG alloys. The indicator responsible for the most risky of the evaluations is indicated at the bottom of the element box. The color relates to the color ramp at the bottom of the figure (Color figure online).

low supply risk (SR) and a high performance parameter, so that the composition would fall in the upper lift quadrant of Fig. 3. A composition with a low performance parameter (thus, falling in the lower left and lower right quadrants) would obviously be not suitable as a BMG. A composition with both a high performance parameter and a 


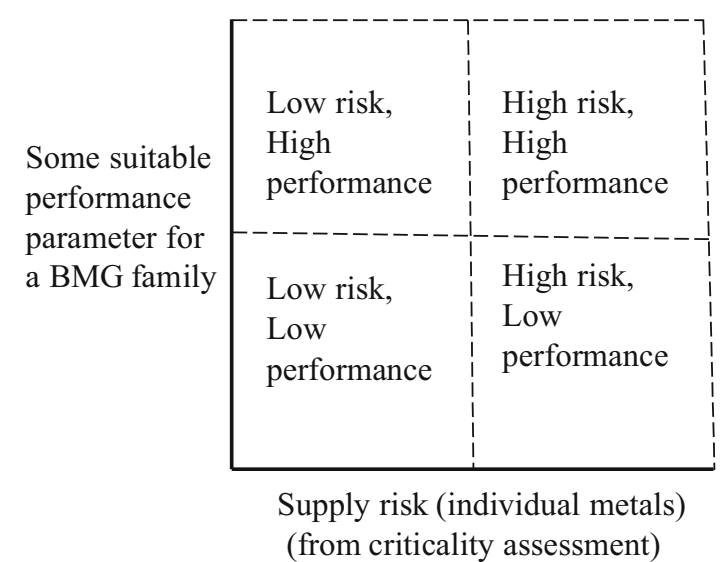

Fig. 3. Speculative diagram to identify BMG groups that combine varying degrees of criticality and performance.

high supply risk (upper right quadrant) might perform well but could perhaps come under supply constraints if employed extensively.

An evaluation of the type suggested in Fig. 3 could be done in several ways. As an example for discussion, we suggest plotting for a given BMG composition the highest constituent SR value on the abscissa and a function of one or more characteristics of the composition on the ordinate. A simple example, but a useful one, is that of selected physical properties of BMG compositions. We choose to express the performance of an individual BMG as the product of yield strength, $\sigma_{\mathrm{y}}$, and fracture toughness, $K_{\mathrm{i}}$. To make such data more meaningful for a relative comparison, we normalize values by their median value, which we determine from a broad selection of BMGs; i.e.,

$$
\begin{aligned}
P_{\mathrm{i}}= & \left(K_{\mathrm{i}}\left(\mathrm{BMG}_{\mathrm{i}}\right) / K_{\mathrm{i}}\left(\mathrm{BMG}_{\mathrm{m}}\right)\right) \\
& \times\left(\sigma_{\mathrm{y}}\left(\mathrm{BMG}_{i}\right) / \sigma_{\mathrm{y}}\left(\mathrm{BMG}_{\mathrm{m}}\right)\right)
\end{aligned}
$$

where $P_{\mathrm{i}}$ is the performance of composition $i$, and subscript $\mathrm{m}$ refers to the median of the values in Table I. In this formulation, a BMG composition that has the fracture toughness and yield strength of the average BMG composition would thus have a performance rating of unity.

To represent the material class of BMGs broadly, we considered overall 22 different alloys (Table I). As a comparison, we chose a representative common steel, stainless steel, titanium, and aluminum alloy. Criticality information for considered alloys are listed in Table I and organized by their performance in Fig. 3. There is a significant performance range among the considered alloys. $\mathrm{Ni}_{62} \mathrm{Pd}_{19} \mathrm{Si}_{2} \mathrm{P}_{17}$ performs more than $100 \%$ better than the median BMG, whereas $\mathrm{Mg}_{65} \mathrm{Cu}_{25} \mathrm{Y}_{10}$ exhibits only $\sim 2 \%$ of the performance of the median BMG. For the established conventional alloys, Ti6V4Al performs comparable to the median BMG, whereas the steels perform $\sim 50 \%$ and aluminum alloys $\sim 10 \%$ of that of the median BMG.
The information from Table I can now be used to generate a performance-criticality matrix of the type indicated in Fig. 3. The results are shown in Fig. 4. The technique populates all four regions of the diagram. From the perspective of this analysis, the most desirable BMG compositions are $\mathrm{Ni}_{62} \mathrm{Pd}_{19}$ $\mathrm{Si}_{2} \mathrm{P}_{17}, \quad \mathrm{Cu}_{49} \mathrm{Hf}_{42} \mathrm{Al}_{9}, \quad \mathrm{Cu}_{60} \mathrm{Zr}_{20} \mathrm{Hf}_{10} \mathrm{Ti}_{10}, \quad$ and $\mathrm{Pt}_{57.5} \mathrm{Cu}_{14.7} \mathrm{Ni}_{5.3} \mathrm{P}_{22.5}$, which are in the upper left quadrant. These alloys are limited by copper and palladium as their highest criticality value. In contrast, the least desirable compositions are those that populate the lower right quadrant: $\mathrm{Au}_{49} \mathrm{Ag}_{5.5} \mathrm{Pd}_{2.3} \mathrm{Cu}_{26.9} \mathrm{Si}_{16.3}, \mathrm{Zr}_{57} \mathrm{Cu}_{15.4} \mathrm{Ni}_{12.6} \mathrm{Al}_{10} \mathrm{Nb}_{5}$, $\mathrm{Fe}_{48} \mathrm{Cr}_{15} \mathrm{Mo}_{14} \mathrm{Er}_{2} \mathrm{C}_{15} \mathrm{~B}_{6}$, and $\mathrm{Ni}_{40} \mathrm{Cu}_{5} \mathrm{Ti}_{17} \mathrm{Zr}_{28} \mathrm{Al}_{10}$. These less desirable alloys are limited by zirconium, silver, and erbium.

It is important to understand why some elements in Table I (e.g., silver) have higher SR values when compared with those of other elements in the BMG compositions. As it happens, the Yale methodology ${ }^{45}$ evaluates SR based on six indicators (Fig. 1). In the case of silver, for example, the depletion time is short (currently $\sim 20$ years), and the companion fraction is high. ${ }^{52}$ Most silver is produced as a byproduct of lead-zinc and copper ores. Other indicators are high for other metals. In Table I, column 7, we indicate the expanded SR metric most responsible for the SR rating of the different BMG compositions. It is clear that because compositions such as BMGs generally use one or more of the less abundant materials, their criticality could prove to be much more significant than is the case for common alloys.

\section{DISCUSSION}

Overall, because criticality depends on the most critical element in an alloy (at least under the methodology employed herein), simpler alloys generally tend to be less critical than those that are more compositionally diverse. This suggests that as a result of their multicomponent nature, generally BMG alloys are more critical than simple alloys. Nevertheless, BMGs are less critical than, for example, high-entropy alloys, which constitute more than five elements, ${ }^{86}$ or superalloys, which often contain more than ten elements. ${ }^{39}$ We do not imply that criticality should be the dominant factor in making compositional choices for any of these types of alloys. Yet, we believe that criticality should be a factor that enters into considerations of compositional choice. In this article, we present one possible approach to taking criticality into consideration.

In the development of an alloy, a broad range of requirements are considered that at least to some extent are controlled by its constituent elements. Specifically, for metallic glasses, element selection is often considered through their collaborative behavior to result in deep eutectics, ${ }^{2,33}$ large negative heat of mixings, ${ }^{2}$ and size difference. ${ }^{2,4,28,87}$ 


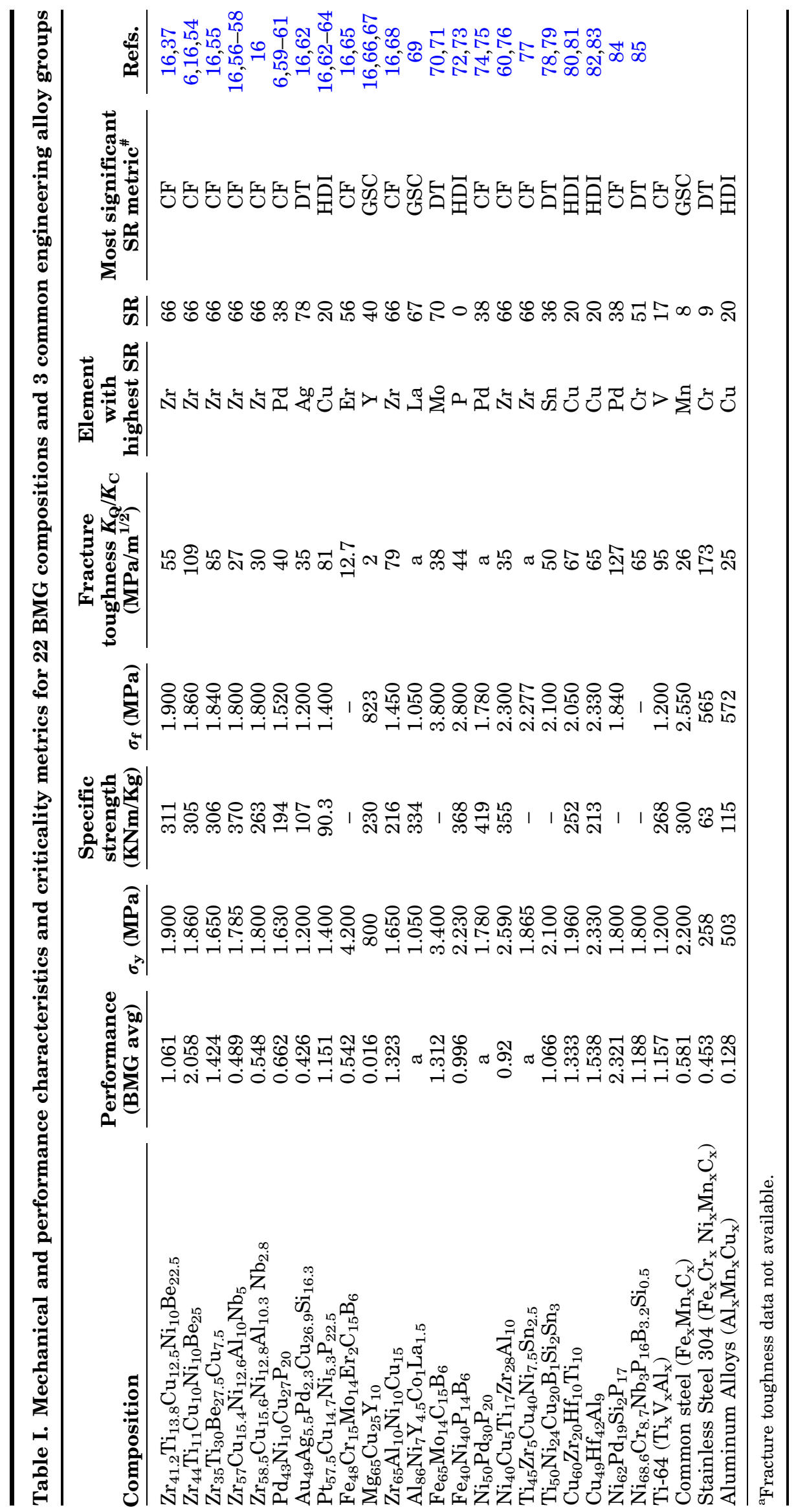




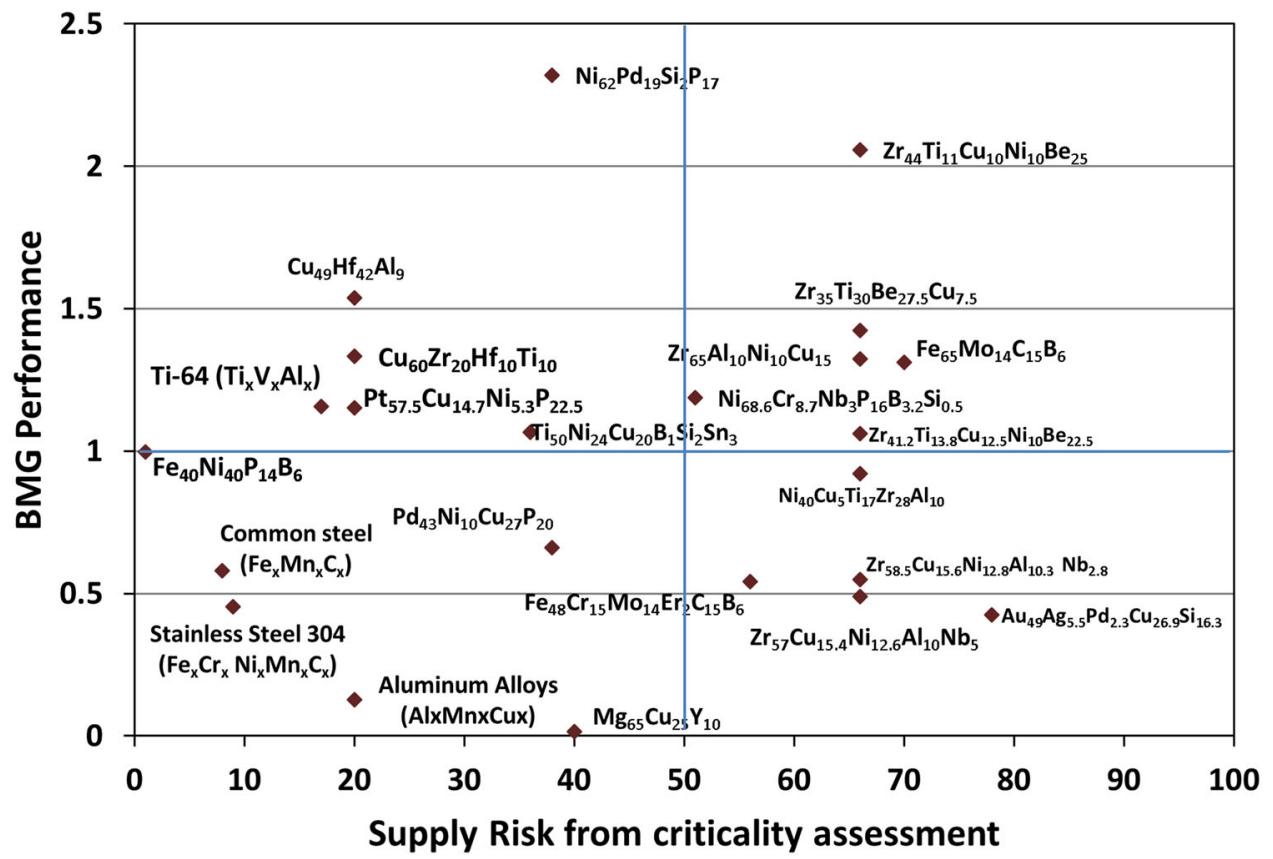

Fig. 4. Performance versus supply risk of BMG alloys and for comparison of conventional steels, Ti-, and Al-alloys.

Individual constituent element properties can be used to estimate material cost and, to some extent, strength and plasticity. ${ }^{88}$ Acknowledging the development status of BMG technology as being on the threshold of wider commercial adaptation, ${ }^{15}$ criticality is another important aspect to be considered when considering BMGs for applications or in the development process of BMGs.

An important aspect of our analysis is that we have chosen to select for the figures the element in a BMG composition that has the highest criticality value; that is, what is plotted on the abscissa of those figures is not an average value for the elements in a BMG composition. The criticality of a BMG alloy, measured in this way, might thus refer to an element present in tiny amounts. Nonetheless, it could be essential to creating the performance desired, so its unavailability would essentially remove the entire BMG alloy from consideration.

It is shown elsewhere ${ }^{47,51}$ that the elements that have high criticalities tend to be "companion metals" (those only available as by-products of host metals in ore deposits), and only those companion metals that have no suitable substitutes for most or all of their uses. It would be preferable to avoid those elements in BMG compositions, if possible. Alternatively, it would be advisable to use highcriticality metals only for small, high-value-added applications, and not in essential technologies where the unavailability of a crucial BMG element could have major consequences.

Elements that have been used in BMGs with highest criticality are $\mathrm{Zr}$ (66), $\mathrm{Ag}$ (78), Mo (70), Cr (51), La (67), and $\operatorname{Er}(56)$. These elements have been essential in warranting a high glass-forming ability in the corresponding BMG alloy. Nonetheless, the importance of these elements varies considerably. Whereas La, Er, Mo, and $\mathrm{Cr}$ might be replaceable and only affect a few alloys, specifically $\mathrm{Zr}$ is the base element for many BMGs. This is because $\mathrm{Zr}$ exhibits deep eutectics with $\mathrm{Be}$ and $\mathrm{Ni}$, as well as exhibits drastic reduction in liquidus temperature with $\mathrm{Cu}$ and $\mathrm{Al}$. Such destabilization of the competing crystalline phase leads generally to an increase in $T_{\mathrm{g}} / T_{\mathrm{l}}$, which indicates an enhanced glass-forming ability (GFA; ease of glass formation). ${ }^{32}$ Furthermore, it has favorable phase diagrams with limited high-temperature intermetallic phases, again avoiding stable competing crystalline phases. Furthermore, $\mathrm{Zr}$ also exhibits often large solubility with many practical elements, most prominent with Ti. This allows for substitution of $\mathrm{Zr}$ with these elements that might yield other benefits such as improved glass-forming ability or enhancement in properties. A possible substitution for $\mathrm{Zr}$ is Hf. Yet, SR for Hf of 53 is still high and would not generally reduce criticality of such alloys. Furthermore, direct substitution of $\mathrm{Zr}$ with $\mathrm{Hf}$ increases density and reduces GFA and general processability.

In general, it is difficult to modify already developed BMG alloys for specific needs (e.g., low criticality). Often, BMG alloys have been developed for GFA, and as a consequence, most modifications to optimize for specific properties have resulted in a reduction of GFA. Instead of modifying existing BMGs, a more promising strategy might be to consider criticality early on in the alloy development process by restricting the pool of considered elements to those with low criticality. 


\section{ACKNOWLEDGEMENTS}

This work was supported by the Department of Energy through the Office of Basic Energy Sciences (\#DE SC0004889).

\section{REFERENCES}

1. A.L. Greer, Science 267, 1947 (1995).

2. A. Inoue, Acta Mater. 48, 279 (2000).

3. J. Schroers, Phys. Today 66, 32 (2013).

4. D.B. Miracle, Nat. Mater. 3, 697 (2004).

5. S.V. Madge, Met. Basel 5, 1279 (2015).

6. W. Chen, Z. Liu, J. Ketkaew, R.M.O. Mota, S.H. Kim, M. Power, W. Samela, and J. Schroers, Acta Mater. 107, 220 (2016).

7. W.H. Jiang, F. Jiang, B.A. Green, F.X. Liu, P.K. Liaw, H. Choo, and K.Q. Qiu, Appl. Phys. Lett. 91, 041904 (2007).

8. W.H. Peter, R.A. Buchanan, C.T. Liu, P.K. Liaw, M.L. Morrison, J.A. Horton, C.A. Carmichael, and J.L. Wright, Intermetallics 10, 1157 (2002).

9. D. Zander and U. Koster, Mater. Sci. Eng., A 375, 53 (2004).

10. L. Liu, C.L. Qiu, Q. Chen, and S.M. Zhang, J. Alloys Compd. 425, 268 (2006).

11. S. Buzzi, K.F. Jin, P.J. Uggowitzer, S. Tosatti, T. Gerber, and J.F. Loffler, Intermetallics 14, 729 (2006).

12. J. Schroers, G. Kumar, T.M. Hodges, S. Chan, and T.R. Kyriakides, JOM 61, 21 (2009).

13. J. Padmanabhan, E.R. Kinser, M.A. Stalter, C. DuncanLewis, J.L. Balestrini, A.J. Sawyer, J. Schroers, and T.R. Kyriakides, ACS Nano 8, 4366 (2014).

14. M. Carmo, R.C. Sekol, S.Y. Ding, G. Kumar, J. Schroers, and A.D. Taylor, ACS Nano 5, 2979 (2011).

15. A.L. Greer, Mater. Today 12, 14 (2009).

16. A. Inoue and N. Nishiyama, MRS Bull. 32, 651 (2007).

17. D.L. Henann, V. Srivastava, H.K. Taylor, M.R. Hale, D.E. Hardt, and L. Anand, J. Micromech. Microeng. 19, 115030 (2009).

18. J. Schroers, T.M. Hodges, G. Kumar, H. Raman, A.J. Barnes, P. Quoc, and T.A. Waniuk, Mater. Today 14, 14 (2011).

19. J. Schroers and N. Paton, Adv. Mater. Process. 164, 61 (2006).

20. Y. Kawamura, H. Kato, A. Inoue, and T. Masumoto, Appl. Phys. Lett. 67, 2008 (1995).

21. H.M. Chiu, G. Kumar, J. Blawzdziewicz, and J. Schroers, Scripta Mater. 61, 28 (2009).

22. J. Schroers, Adv. Mater. 22, 1566 (2010).

23. W.L. Johnson, G. Kaltenboeck, M.D. Demetriou, J.P. Schramm, X. Liu, K. Samwer, C.P. Kim, and D.C. Hofmann, Science 332, 828 (2011).

24. J.A. Bardt, G.R. Bourne, T.L. Schmitz, J.C. Ziegert, and W.G. Sawyer, J. Mater. Res. 22, 339 (2007).

25. R. Martinez, G. Kumar, and J. Schroers, Scripta Mater. 59, 187 (2008).

26. S. Ding, Y. Liu, Y. Li, Z. Liu, S. Sohn, F. Walker, and J. Schroers, Nat. Mater. 13, 494 (2014).

27. T. Egami and Y. Waseda, J. Non.Cryst. Solids 64, 113 (1984).

28. K. Zhang, B. Dice, Y.H. Liu, J. Schroers, M.D. Shattuck, and C.S. O'Hern, J. Chem. Phys. 143, (2015).

29. C.V. Thompson and F. Spaepen, Acta Metall. 31, 2021 (1983).

30. K. Zhang, M.L. Wang, S. Papanikolaou, Y.H. Liu, J. Schroers, M.D. Shattuck, and C.S. O'Hern, J. Chem. Phys. 139, 123 (2013).

31. W. Klement, R.H. Willens, and P. Duwez, Nature 187, 869 (1960).

32. D. Turnbull, Contemp. Phys. 10, 473 (1969).

33. S.Y. Ding, J. Gregoire, J.J. Vlassak, and J. Schroers, J. Appl. Phys. 111, 494 (2012).

34. W.L. Johnson, MRS Bull. 24, 42 (1999).

35. A. Inoue and A. Takeuchi, Acta Mater. 59, 2243 (2011).
36. G. Kumar, A. Desai, and J. Schroers, Adv. Mater. 23, 461 (2011).

37. R.D. Conner, W.L. Johnson, N.E. Paton, and W.D. Nix, J. Appl. Phys. 94, 904 (2003).

38. M.C.S. U.S. Geological Survey, (2016), http://dx.doi.orf/10. 3133/70140094.

39. X.Y. Du and T.E. Graedel, Environ. Sci. Technol. 45, 4096 (2011).

40. M.M. Poulton, S.C. Jagers, S. Linde, D.V. Zyl, L.J. Danielson, and S. Matti, Ann. Rev. Environ. Res. 38, 345 (2013).

41. EC, European Commission, Report of the Ad-hoc Working Group on defining critical raw materials (2014).

42. NRC, Minerals, Critical Minerals, and the U.S. Economy (Washington, DC: U.S. National Research Council, National Academies Press, 2008).

43. BGS, Risk List 2012: An Updated Supply Risk Index for Chemical Elements or Element Groups Which are of Economic Value. (Nottingham, UK: British Geological Survey, 2012).

44. L. Erdmann and T.E. Graedel, Environ. Sci. Technol. 45, 7620 (2011).

45. T.E. Graedel, R. Barr, C. Chandler, T. Chase, J. Choi, L. Christoffersen, E. Friedlander, C. Henly, C. Jun, and N.T. Nassar, Environ. Sci. Technol. 46, 1063 (2012).

46. S. Glöser, L. Tercero Espinoza, C. Gandenberger, and M. Faulstich, Resour. Policy 44, 35 (2015).

47. S. Panousi, E. Harper, P. Nuss, M.J. Eckelman, A. Hakimian, and T. Graedel, J. Ind. Ecol. 95, 193 (2015).

48. N.T. Nassar, R. Barr, M. Browning, Z. Diao, E. Friedlander, E. Harper, C. Henly, G. Kavlak, S. Kwatra, and C. Jun, Environ. Sci. Technol. 46, 1071 (2012).

49. P. Nuss, E. Harper, N. Nassar, B.K. Reck, and T. Graedel, Environ. Sci. Technol. 48, 4171 (2014).

50. E. Harper, Z. Diao, S. Panousi, P. Nuss, M.J. Eckelman, and T. Graedel, Resour. Conserv. Recycl. 95, 193 (2015).

51. N.T. Nassar, X. Du, and T. Graedel, J. Ind. Ecol. 19, 1044 (2015).

52. T. Graedel, E. Harper, N. Nassar, P. Nuss, and B.K. Reck, Proc. Natl. Acad. Sci. U.S.A. 112, 4257 (2015).

53. E.M. Harper, G. Kavlak, L. Burmeister, M.J. Eckelman, S. Erbis, V. Sebastian Espinoza, P. Nuss, and T. Graedel, J. Ind. Ecol. 19, 628 (2015).

54. J. Schroers, Q. Pham, and A. Desai, J. Microelectromech. Syst. 16, 240 (2007).

55. J. Qiao and Y. Zhang, Intermetallics 19, 149 (2011).

56. J. Park, G. Wang, S. Pauly, N. Mattern, D. Kim, and J. Eckert, Metall. Mater. Trans. A 42, 1456 (2011).

57. H. Choi-Yim, R. Busch, U. Köster, and W. Johnson, Acta Mater. 47, 2455 (1999).

58. J. Lewandowski, W. Wang, and A. Greer, Philos. Mag. Lett. 85, 77 (2005).

59. L. Watanabe, S. Roberts, N. Baca, A. Wiest, S. Garrett, and R. Conner, Mater. Sci. Eng., C 33, 4021 (2013).

60. W.H. Wang, J. Appl. Phys. 99, 093506 (2006).

61. J. Ketkaew, Z. Liu, W. Chen, and J. Schroers, Phys. Rev. Lett. 115, 265502 (2015).

62. J. Schroers, B. Lohwongwatana, W.L. Johnson, and A. Peker, Mater. Sci. Eng., A 449, 235 (2007).

63. J. Schroers and W.L. Johnson, Phys. Rev. Lett. 93, 255506 (2004).

64. W.H. Wang, J. Appl. Phys. 111, 123519 (2012).

65. S. Guo, J. Qiu, P. Yu, S. Xie, and W. Chen, Appl. Phys. Lett. 105,161901 (2014).

66. A. Inoue and T. Masumoto, Mater. Sci. Eng., A 173, 1 (1993).

67. G. Yuan, T. Zhang, and A. Inoue, Metall. Mater. Trans. 44, 2271 (2003).

68. W. Li, B. Wei, T. Zhang, L. Zhang, and Y. Dong, Metall. Mater. Trans. 46, 2954 (2005).

69. B. Yang, J. Yao, J. Zhang, H. Yang, J. Wang, and E. Ma, Scripta Mater. 61, 423 (2009).

70. J. Lewandowski, X. Gu, A.S. Nouri, S. Poon, and G. Shiflet, Appl. Phys. Lett. 92, 091918 (2008). 
71. X. Gu, S.J. Poon, and G.J. Shiflet, J. Mater. Res. 22, 344 (2007).

72. K. Yao and C. Zhang, Appl. Phys. Lett. 90 (6), 061901 (2007).

73. D. Ast and D. Krenitsky, Mater. Sci. Eng. 23, 241 (1976).

74. K. Wang, T. Fujita, Y. Zeng, N. Nishiyama, A. Inoue, and M. Chen, Acta Mater. 56, 2834 (2008).

75. Y. Zeng, N. Nishiyama, T. Wada, D.V. Louzguine-Luzgin, and A. Inoue, Metall. Mater. Trans. 47, 175 (2006).

76. D. Xu, G. Duan, W.L. Johnson, and C. Garland, Acta Mater. 52, 3493 (2004).

77. K. Kim, J. Das, X. Wang, X. Zhang, J. Eckert, and S. Yi, Philos. Mag. Lett. 86, 479 (2006).

78. T. Zhang and A. Inoue, Mater. Sci. Eng., A 304, 771 (2001).

79. X. Xi, D. Zhao, M. Pan, W. Wang, Y. Wu, and J. Lewandowski, Phys. Rev. Lett. 94, 125510 (2005).
80. A. Inoue, W. Zhang, T. Zhang, and K. Kurosaka, J. NonCryst. Solids 304, 200 (2002).

81. P. Wesseling, T. Nieh, W. Wang, and J. Lewandowski, Scripta Mater. 51, 151 (2004).

82. P. Jia, H. Guo, Y. Li, J. Xu, and E. Ma, Scripta Mater. 54, 2165 (2006)

83. P. Jia and J. Xu, J. Mater. Res. 24, 96 (2009).

84. X. Liu, Y. Shao, S.Y. Lu, and K.F. Yao, J. Polym. Sci., Part B: Polym. Phys. 53, 463 (2015).

85. J.H. Na, M.D. Demetriou, M. Floyd, A. Hoff, G.R. Garrett, and W.L. Johnson, Proc. Natl. Acad. Sci. U.S.A. 111, 9031 (2014).

86. Y.F. Ye, Q. Wang, J. Lu, C.T. Liu, and Y. Yang, Mater. Today 19, 349 (2016).

87. K.J. Laws, D.B. Miracle, and M. Ferry, Nat. Commun. 6, 8123 (2015)

88. W.H. Wang, J. Appl. Phys. 99 (9), 093506 (2006). 